The increase in the amount of oxygen injected per day was modulated according to the change in load of the manure to be treated directly related with the feeding level.

During the treatment, the different pollution parameters increased progressively and reached a plateau at a concentration of 30 to $35 \mathrm{~g} / 1$.

The dissolved oxygen concentration was always around $\mathrm{I} \mathrm{mg} / \mathrm{l}$ for a ventilation rate of I 2.5 to 50 p. Ioo. During this period, no form of oxydated nitrogen could be determined.

On the contrary, during the second period the nitrite concentration increased progressively and reached $2200 \mathrm{~g} / 1$ at the 13 th week. At the 7 th week, $500 \mathrm{mg} / 1$ nitrate were determined, whereafter the concentration fell abruptly (for a tiitrite concentration of $1200 \mathrm{mg} / 1$ ).

The load recordings showed an epuration yield for total dry matters and T.K.N. of 40 p. 100 identical in the two treatments. On the contrary, the ammonia nitrogen decreased of $44 \mathrm{p}$. 100 during the second treatment, leading to a larger oxygenation: the lower the ventilation rate, the higher the temperature increase.

It seems that $30 \mathrm{kw} /$ pig present corresponds to an optimum deodorization treatment, the apparatuses working $40-60 \mathrm{p}$. Ioo of the time.

\title{
Variation in pig manure composition during storage
}

\author{
C. R. BERNARD, Michèle HEDUIT \\ U.C.A.A.B., Chierry, 02400 Chateau-Thierry \\ G.I.D.A., I.T.P., I49, rue de Bercy, 75595 Paris Cedex ra
}

A concrete silo $3.4 \mathrm{~m}$ high and with a diameter of I metre was used for a period of 3 months to study the variation in the main physicochemical parameters, the volatile fatty acid contents, the bacterial flora and the sludge load of pig manure at three sampling stages.

A sedimentation fastly occurred at the beginnitig of the storage. The mineral contents (determined on the dry product) tended to become uniform with time at the different stages. The ammonia nitrogen level almost did not change and was identical at the different stages. Phosphorus and calcium, mainly in the insoluble form, wete concentrated at the decantation stage. Only traces of lactic acid could be found. The acetic, butyric and propionic acid levels, increasing with time, showed values of the same magnitude at the different stages.

The mesophilic aerobic total flora and the number of spores of sulfito reducing Clostridium decreased during the first part of the sudy and then returned almost to the initial level. On the contrary, the amount of faecal coliforms Eschevichia coli, enterobacteria and streptococci decreased and disappeared after three months. As for the pollution parameters studied (D.B.O. 5 and D.C.O.), the highest values were obviously found in the decantation product which is the richest in dry matter, suspended matters and crude fibre. The liquid supernatent showed a D.C.O./ D.B.O. 5 ration of 2.5 . to 3 corresponding to a more easily biodegradable effluent. 